\title{
NL Switching as a Compensatory Strategy of Indonesian EFL School Students and Its Pedagogical Implication
}

\author{
Endang Fauziati*, Abdillah Nugroho, Susiati, Muhamad Taufik Hidayat \\ Universitas Muhammadiyah Surakarta, Indonesia
}

Received July 30, 2019; Revised September 16, 2019; Accepted September 23, 2019

\begin{abstract}
Copyright $\mathrm{O} 2019$ by authors, all rights reserved. Authors agree that this article remains permanently open access under the terms of the Creative Commons Attribution License 4.0 International License
\end{abstract}

\begin{abstract}
This study aimed to provide an empirical evidence of NL Switching as compensatory strategy of EFL school students in their written communication. The focus was to identify, describe, and explain the linguistic realization and patterns of the NL switching to compensate for their missing language knowledge and proposing its pedagogical implication. The data were in the form of words, phrases, and sentences reflecting NL switching as compensatory strategy, which were elicited from the students' English free composition and results from interview. The data were identified, described, and explained based on relevant perspectives. The results indicated that the lexical switching as compensatory strategy in communication was in the form of Indonesian naturalized borrowed words from Arabic, Indonesian words, Indonesian cognate, and Indonesian abbreviation, while the syntactical switching was in the form of Indonesian collocation, Indonesian construction, and Indonesian conjunction. The findings of this study provide empirical evidence on NL switching in Indonesian EFL school students' written communication.
\end{abstract}

Keywords Lexical \& Syntactical Strategy, NL Switching, Compensatory Strategy, Cultural-loaded Words

\section{Introduction}

EFL classroom is commonly the only place where learners are engaged in communication using English. Sometimes, however, while speaking and writing, they face some difficulties to keep the flow of communication. To overcome this problem they use code switching as compensation strategy. Compensation or compensatory strategy comes under the broader term communication strategies or strategic competence, the strategies employed by creative learners to circumvent their linguistic difficulties or inadequacies in the second language (L2).
Dornyei (1997) stated that this term first raised as researchers noticed the mismatch between EFL learners' linguistic resources and communicative intentions which led to language phenomenon whose main function was to cope with problems in L2 communication. He presented taxonomy of communication strategies, consisting of two kinds which reveal two opposite directions in communication, avoiding and compensating. Through avoiding, learners try to avoid topic areas that pose language problems and through compensating, they find ways to compensate for the difficulties.

That is to say, compensatory strategies are the ones used by EFL learners in production of the language they are learning. The strategies are made up for compensating an insufficient repertoire of vocabulary and grammar (Oxford, 2003). When facing with problems in expressing their ideas in the target language, EFL learners may find a solution, such as making use of various cognitive compensatory strategies to directly handle the problems. The purpose of the use of compensatory strategies is to make up for an inadequate repertoire of vocabulary and grammar. For this end, EFL learners commonly find solution from their native language (NL), that is, by code switching to their NL in terms of grammar and vocabulary. These strategies are commonly activated when they want to achieve the oral and written communication goal but having insufficient linguistic resources (Olivares \& Fonseca, 2013). Oxford (2003) states that compensation strategies enable learners to use the target language for comprehension and production despite their limitations in the knowledge. Compensation strategies are used to make up for an inadequate repertoire of lexical and grammatical knowledge. Oxford (2003) identifies compensatory strategy as one of six major groups of L2 learning strategies, i.e. cognitive strategies, metacognitive strategies, memory-related strategies, compensatory strategies, affective strategies, social strategies. She (2003) divides compensatory strategy into guessing intelligently and overcoming limitations in speaking and writing. And strategy to overcome limitations consists of eight strategies 
of which one of them is switching to the mother tongue or commonly called code switching. Meanwhile, Yaman et al. (2013) notice two approaches to investigate communication strategies: the interactional view which is related to the interaction process between learners and their interlocutors and the psycholinguistic view which is associated with strategies for overcoming linguistic knowledge limitations. From a psycholinguistic view, Faerch and Kasper quoted in Yaman et al. (2013) proposed two possible strategies, avoidance and achievement strategies. Achievement strategies consist of compensatory strategies and retrieval strategies. Thus, compensation strategy of code switching belongs to psycholinguistic process used by language learners to overcome their limitations in language knowledge.

With regards to code switching, Myers-scotton (2006) defines it as the use of two language varieties in the same communication. Code-switching is a change of a code (language) from one language to another in the same utterance or in a conversation. It takes place at various points in an utterance such as between sentences, clauses, phrases, and words. It is a very common phenomenon among bilinguals, including in EFL context. EFL students are observed combining and shifting between two languages (native and target language). They use code switching as compensatory strategy to overcome linguistic problems in oral and written communication (Modupeola, 2013). They express their ideas using their varied linguistic repertoire when it is necessary. By analyzing the EFL practice in a classroom, this study tries to shows how code switching (NL switching) can be used by the students to overcome their lexical as well as grammatical problems.

The main interest of this study is to investigate the EFL school students' use of NL switching as compensatory strategy in written communication to overcome their linguistic gabs in expressing their ideas in English. Accordingly, the findings of this study attempts to contribute to the field of EFL education as it provides insights about the language practice in EFL classrooms. EFL teachers may have positive attitudes towards NL switching phenomenon and see the advantages of how EFL students handle their vocabulary and grammatical gaps in the TL which could improve their confidence to learn.

There have been lots of relevant studies such as conducted by Chung (2006), Muin (2011), Das (2012), Jamshidi \& Navehebrahim (2013), Halim \& Maros (2014), Nyambura (2015), Zidouni (2016), Andayani (2016), Bhatti et.al, 2018, and Fitriani (2019) on communication strategy of NL switching by EFL learners or bilinguals speakers with various language background (i.e., Korean, Indonesian, Bangladeshi, Persian, Malay, Algerian, Pakistan). They were particularly interested in finding reasonable explanations for the use of NL switching as communication strategy, especially in oral production. They also tried to disclose how NL switching can facilitate communication between EFL students and teachers and between bilingual interlocutors. For the purpose of the present study, these recent studies are worthy to review to show the novelty of this study.

The reviewed studies particularly investigated NL switching as communication strategy to facilitate oral communication breakdown. The communication breakdown commonly came from the students' lack of linguistic competence, especially finding the right vocabulary and grammar to create correct sentences. To compensate this inadequacy they chose strategy of NL switching (Zidouni, 2016; Fitriani, 2019). The type of NL switching commonly used was literal translation (Fitriani, 2019). Moreover, this could help students to understand and to be understood when unfamiliar expressions occur (Zidouni, 2016). Chung (2006), Muin (2011), and Das (2012) found that NL switching was used as a communicative strategy by bilinguals to facilitate communication by lowering language barriers and to manifest cultural identity. It was a versatile strategy to meet the complex communicative demands between or within the interlocutors. Meanwhile, Halim \& Maros (2014) added that in face book, it functioned as quotation, addressee specification, reiteration, message qualification, clarification, emphasis, checking, indicating emotions, availability, principle of economy.

NL switching was also used as communication strategy in EFL classroom, especially when the students could not express their ideas in English, they tended to switch to mother tongue (Muin, 2011; Fitriani, 2013, Andayani, 2016). Mother tongue switch functioned as an effective strategy both by EFL students and teachers to increase the efficiency for conveying information and to overcome communication difficulties (Jamshidi \& Navehebrahim, 2013; Nyambura's, 2015; Zidouni, 2016; Andayani, 2016; Bhatti et.al, 2018; Fitriani, 2019). EFL students felt more comfortable and enjoyed greater competence (Jamshidi \& Navehebrahim, 2013). They also felt more confidence and motivated to take part in meaningful interaction as they could easily involved in communication without being afraid of language gaps (Zidouni, 2016). Three types of NL switching occurred during the EFL classes were tag-switching, intra-sentential switching and inter-sentential switching (Andayani, 2016; Bhatti et al. 2018) and the most dominant type used was intra-sentential switching (Andayani, 2016). In addition, teachers commonly switched to NL to build solidarity and intimate relationships with the students before, during, and after the lessons (Bhatti et al., 2018).

The previous studies reviewed were devoted to communication strategy of NL switching among bilinguals as well as EFL teachers and learners with Korean, Indonesian, Bangladeshi, Persian, Malay, Algerian, and Pakistani language background. The present study shares with the previous reviewed studies in terms of shedding light on the phenomenon of NL switching, especially by students. Besides, they attempt to examine its appearance 
in educational setting, namely, EFL classroom. However, this study is different from its predecessors in the following aspects. Most studies were conducted in EFL higher education classrooms and university students as the research subjects. The current study was conducted in EFL school context and secondary school students as the research subjects. In addition, the reviewed studies focused on NL switching in spoken context, whereas the current study centered its attention on EFL learners' written context. Importantly, despite the recognition that EFL learners with various language background may switch to their NL as a communication strategy, some of the reviewed studies emphasized mainly on the type and function of code switching. NL switching is an inevitable feature in Indonesian EFL classrooms it is common for the students to resort to it as a compensatory resource to keep communication going. How NL switching was linguistically realized in Indonesian students' written communication was not yet disclosed. Therefore, to fill in the gap, the present study shed lights on the linguistic realization and the pattern of NL switching as a compensatory strategy in written communication of Indonesian EFL school learners and proposed its pedagogical implications. In addition, the reviewed studies which relate NL switching as communication strategy posited that EFL learners commonly confronted with communication problems, including grammar and vocabulary. They required an L2 proficiency level above that of the learners, therefore, they need to be trained compensatory strategies to cope with the difficulties. And this could play a facilitative role for compensatory purposes to overcome the problems. However, how NL switching manifests itself linguistically as a compensatory strategy in written communication of Indonesian EFL school students is not yet much disclosed. And this becomes the novelty of the current study. This study, therefore, was meant to complete and extend the previous ones, particularly in Indonesian school context. The overall aim of this study was to promote good understanding and the manifestation of the phenomenon of NL switching as a compensatory strategy in written communication among Indonesian EFL school students.

This continuing interest on communication strategy of NL switching in EFL learning can be attributed to the fact that its occurance on EFL classroom is quite apparent since it is an inevitable cognitive process in second language learning. Hence, the present study raised the following research objectives: (1) to describe the linguistic realization of NL switching as compensatory strategies both at grammatical as well as lexical level; (2) to reveal the patterns of NL switching as compensatory strategies; and (3) to propose its pedagogical implication.

\section{Methodology}

This case study attempted to reveal the nature of NL switching as compensatory strategy in written communication by Indonesian EFL school students. This study used a qualitative approach of SLA in a classroom context or instructed SLA (Ellis, 2006). The research subjects were 80 school students of grade eleven of Muhammadiyah Senior High School of Surakarta, Indonesia. The students' native language background is Indonesian and they had learnt English as a foreign language through formal schooling or in non-natural evironment for approximately 6 years.

The qualitative primary data were in the form of words, phrases, and sentences reflecting compensatory strategy of NL switching collected from the students' free compositions. Techniques of triangulation (in depth interview) and inter-rater were used to ensure the data credibility. The secondary data were the information related to the NL switching collected through interview with 10 students who were purposively selected on the basis of their availability. This helped to obtain a better understanding of the NL switching practices as cognitive compensatory strategy.

To elicit the data, the research subjects were assigned to write composition as it is believed to be one of the best forms of closely observed second language production. The students could use freely any patterns they had learned for their own writing. The students' composition was a task directly performed by the subjects in the classroom. They were given topics "My self, my daily activities, my last experience" and they were free to write any thing related to the topics. The composition was around 200-300 words. The whole writing process was directly under the researchers' supervision and the students made no preparation in advanced. As to make the data more reliable, the data were rated by three researchers.

The data were identified on the basis of James's (2014) framework, particularly linguistic categories and comparative taxonomy to identify the instances of the NL switching. The collected data were classified in order to depict the linguistic realization of compensatory strategy of NL switching and the patterns of the switching. The description of linguistic realization was conducted by using James's (2014) framework and Poplock's (2013) and Kishe's (2017) classification of tag, inter-sentential, intra-sentential switching, literal translation switching was used to describe the pattern of NL switching. The findings were then discussed and explained based on the relevant theories. Finally, some pedagogical implications were drawn.

\section{Research Findings}

\subsection{Linguistic Realization of NL Lexical Switching as Compensatory Strategy}

This section presents the qualitative analysis of the instances of NL switching as compensatory strategy. The 
data indicated that the students switched to mother tongue as compensatory strategy when dealing with cultural-loaded words. Cultural-loaded words, according to Newmark in Guan \& Zhao (2016), whether single-unit lexemes, phrases or collocations are those which are particularly tied to the way of life and its manifestations that are peculiar to a community that uses a particular language as its means of expression. They directly or indirectly reflect national culture in the structure of words and expressions. As the data indicated that such words posed a real problem for the students to express in English. To compensate this problem, the students found recourse to the vocabulary repertoire already available in their mind and NL switching was applied to texts they wrote in English. The analysis of the data yielded four types of linguistic realizations of NL switching as a compensatory strategy, involving Indonesian naturalized borrowed words from Arabic, Indonesian words, Indonesian cognate, and Indonesian abbreviation.

The Indonesian naturalized borrowed words from Arabic was used as compensatory strategy as most of the research subjects were Moslems and they commonly conducted sacred practices or rituals such as prayers daily or annually as part of their culture. And the Moslem prayers are commonly chanted in Arabic. Hence, a lot of Arabic words related to Moslem rituals have been borrowed and naturalized into Indonesian, for examples the words sholat (daily prayer), shubuh (morning prayer), dhuhur (noon prayer), wudhu (ablution) Romadhon (the fasting month), Idul fitri (celebration of breaking the fast that marks the end of the fasting month), and silaturahmi (visiting relatives to maintain harmonious relationships).

Expressing their daily activity related to rituals was not an easy task to do for the students. As a result they compensated through NL switching to maintain communication, such as in sentences "I am pray Shubuh in the morning and take a bath; And I am pray dhuhur at 12.00 a.m.; After praying Idul Fitri, I want to visit my grand mother; My big family and I silaturahmi with my uncle family; Before praying we take wudhu to clean our body". The words sholat, shubuh, dhuhur, wudhu, Romadhon, Idul fitri, and silaturahmi are associated with cultural-bound words. Such words were difficult for the students to express in English, henceforth they switched to their NL to compensate this difficulty as these words were the vehicle for their cultural manifestation. Which follows are the examples.

(1) We are muslim so we wear hijab. (head cover)

(2) Every Friday I go to mosque for sholat Jum'at. (friday prayer or congregational prayer)

(3) After we pray idul fitri we do khalal bi khalal. (social gatherings to celebrate Eid ul Fitr)

(4) During ramadhon we pray tarawih with family. (night prayer during ramadhon)

The second form was Indonesian words, such as rujak (Indonesian traditional fruit and vegetable salad dish), pecel sayur (traditional Javanese salad, consisting of mixed vegetables in a peanut sauce dressing,), ketoprak Jakarta (Indonesian vermicelli noodles with tofu and peanut sauce originated from Jakarta), and gado-gado (Indonesian vegetable salad with peanut dressing). Such words are also associated with Indonesian culture, representing unique features of Indonesian, especially Javenese, food and these were problematic for the students. To maintain communication, they used these cultural-loaded words or specific expressions in their writings. Below are the examples.

(1) He like Pecel ayam very much.

(2) We eat gado gado at school canteen.

(3) My favorite food is rujak and gado gado.

(4) I usually breakfast with ketoprak Jakarta before going to school.

Just like other people, the students had their own cultural background which was deeply entrenched in their minds, and thus reflected in their communication. In this case, the students were Javanese who were very familiar with Javanese culture and Javanese food. The aforementioned cultural loaded words for Javanese food were unique in Javanese culture. These words were embedded with rich cultural connotations, therefore, they were difficult to be rendered into English. It was truly reasonable that in order to maintain the communication they used these cultural-loaded expressions as in examples below.

(1) I love the cow and every day I give it damen. (rice straw prepared for cattle feed)

(2) My mother go to the market by becak. (3 wheels rickshaw driven by human)

(3) On Sundays I practice karawitan with my friends in school. (traditional music orchestra)

The students also used cognate, that is, "a word in one language which is comparable in style and meaning to a word in another language because both languages are associated" (Richards \& Schmidt, 2002). As the data showed that Indonesian cognate such as aksesori (accessory), presiden (president), lirik (lyric), famili (family), restoran (restaurant). Such vocabulary items are normally interconnected meaningfully with English, however, they do not share phonological and orthographic form. These are often referred to as indirect cognates. Such cognates triggered the students to switch to their NL. In fact, these cognates share similarity in meaning only and not in phonological and orthographic form. The code switching was unavoidable as it helped them express their ideas in English. The data indicated that the students used Indonesian cognates in their writing to compensate their inadequate vocabulary repertoire. What follows are the examples.

(1) SBY is a presiden of Indonesia.

(2) The goat had full energi after eat the grasses.

(3) In a valley, there lived a monkey famili.

(4) The Pisson sang three lirik of the song. 
(5) We eat in the restaran after jogging.

Next, the students switched to their NL in the form of Indonesian abbreviation such as $S D N$ which stands for Sekolah (school) Dasar (elementary) Negri (state owned), $S M P$ for Sekolah (school) Menengah (secondary) Pertama (first), SMA for Sekolah (school) Menengah (secondary) Atas (senior), $P L N$ for Perusahaan (company) Listrik (electricity) Negara (state-owned), and $L K B N$ for Lembaga (agency) Kantor (office) Berita (news) negara (state-owned). These initialisms were culturally embedded, therefore, it was likely that the students' NL cultural features brought into their written communication as the medium for their cultural manifestation. Some examples found in the data are as follows.

(1) My brother is 8 years and he is school in SDN Kleco

(2) My sister is a student of SMP I now.

(3) My father work in PLN.

(4) My father work in LKBN"

(5) My brother school in SMP Muh 4 SKA.

\subsection{Linguistic Realization of NL Grammatical Switching}

Grammar structures were troublesome areas of language that Indonesian senior high-school students faced when writing in English. As a result, they made use of what was already available in their mind, that is, their NL grammar. They switched to NL grammatical structures to compensate their limited knowledge of target language grammar. The data indicated that the switching to NL grammar was realized in the use of Indonesian collocation, passive construction, negative construction, and conjunction.

The first syntactical realization of NL switching was a collocation, that is, sequences of lexical items which normally occur together. Language is not made up of words that may be used together in free variation. Words have a certain tolerance of compatibility (Baker, 1992) since collocation pattern can be culture-specific. Words which collocate well in Indonesian do not always so in English. As the students did not fully grasp these items and the same time they were expected to express themselves in English, they turned to their NL to compensate the difficulties.

The data revealed that the students commonly thought an idea in Indonesian first then translated it into English. For example, in English, a rare or endangered animal in Indonesian is binatang langka and the students literally translated it into English seldom animal. Seldom in Indonesian means langka and animal in Indonesian is binatang. The student wrote "In Indonesia komodo is seldom animal in komodo island". Another example was house cat for domestic cat as shown in the data "Kitty is name of my house cat". Some other examples of NL switching in collocation are as follows.

(1) Beside the study table is a cupboard.
(2) In Indonesia komodo is protection animal in komodo island.

(3) Siti's job was a worker garden.

(4) I have two rooms, a study room and a sleep room.

The next syntactical realization of NL switching found in the data was Indonesian word order of noun phrase. The data revealed that when the students wrote in English, some of their NL word order showed up in their written communication, including NL noun phrase. The students employed NL word order of noun phrase to compensate the linguistic gab as they did not fully understand the constituent ordering within the determiner phrase in English. For examples, the students wrote eyebrows dark, hair long black, body tall. Other examples of NL switching in noun phrase are shown in the data samples below.

(1) After finish SMA I study in university Indonesia (Indonesia University).

(2) I don't like subject mathematics (mathematics subject) and history.

(3) She is artists Indonesia, great and intelligent person.

(4) We have a competition carry out to make a palace sand.

The data also indicated grammatical switching in the passive construction. Passive construction is commonly used as a strategy that allows language users to avoid mentioning the agent. In general, the students had adequate knowledge of the structure of passive voice. However, they often had a considerable problem when using it in sentences. For examples, they wrote "I am told to do my homework before sleep; I study at SMA II Surakarta because it is commanded by my father; The breakfast, lunch and dinner is prepared by my mother; The bedroom is cleaned by myself; Some books read by them in the library every week". Such rethorical style certainly belongs to Indonesian, the students' NL. Markus (2002) stated that Indonesians tended to talk about things and people around them rather than talking about themselves. Therefore, they put forward the object (a thing or another person) being affected by an action expressed in the verb and put the agent later in the sentence.

The NL switching also appeared in negation, that is, a semantic concept used to express an idea opposing the affirmative. In Indonesian, negation can be made simply by placing the word tidak (no) before the main verb. As English negative construction was complex, students used the already available knowledge in their mind, that is, their NL grammar. They simply placed tidak (no/not) before verb, as an example Saya (I) biasanya (usually) tidak (not) makan (have, eat) pagi/sarapan (breakfast). Hence, the students wrote "In the morning I usually not have breakfast; My father not work again, he is pension". They switched to NL as they had the compelling need to communicate their idea in English. The data also indicated that during the English writing process the students might use the two languages (English and Indonesian) background system 
interchangeably. For example, they wrote "I don't like subject mathematics because not understand"; I don't like Biology subject because not interested". In this case, the students commonly acquired the constituent "I don't like" as a prefebricated pattern. Other examples taken from the data are as follows.

(1) My score in SMP not good

(2) In the morning I not breakfast but I not forget dinner.

(3) After that I realized that he not best for me.

(4) My experience not forget is when I go to the beach with my friend.

The NL switching at grammatical level was also realized in the use of adverb of manner, the one used to show the way or how something is done. An adverb can be added to a verb to modify its meaning. In Indonesian, adverb of manner is simply formed by adding the word dengan (meaning with in English) to an adjective; for example, dengan (with) gembira (happy), dengan (with) keras (hard). As the students lacked the target language knowledge, they switched into their NL as this was already available in their mind for the written communication need. Some sentences revealed in the data were as follows.

(1) That's why she starts studying with hard to make her dream come true

(2) My English teacher is most beautiful in my school; She always talks to me with happy

(3) I want to get married and have children and live with happily.

(4) My score in mathematics not good because I don't study with diligent.

\subsection{The Patterns of Compensatory Strategy of NL Switching}

The results revealed four patterns of NL switching as compensatory strategy in the students' written communication, namely: inter-sentential switching, code mixing, literal translation switching, and intra-sentential switching. The occurance NL switching in the students' written communication was very likely functioned as congnitive compensatory strategy used to make up for their inadequate repertoire of vocabulary and grammar. When faced with problems in communicating their ideas in English, the students handled it by switching into their NL in various patterns.

Inter-Sentential Switching: This involves switching at sentential boundaries where one clause or sentence was in English as the TL and the next clause or sentence was in Indonesian, the students' NL. In their attempts to bridge the gap of their linguistic knowledge, the students had a tendency to alternate between two languages, English and Indonesian in the context of a single text. In this context, they switched from English to Indonesian whenever they had difficulty related to TL lexical and grammatical items. However, the incorporation of the constituents of the NL into the TL was done in inappropriate way. Most of the students' NL switching could be categorized into intra-sentencial code-switching (Myusken, 2000). What follows are the examples.

(1) My friend name is Indra. He live in kampung or desa (village) Tohudan.

(2) Santi love him and she is always galau (upset).

(3) Before going to school I usually breakfast with nasi liwet (rice cooked in coconut milk, chicken stock, lemongrass, and Indonesian bay leaves).

(4) They always prayed to get beasiswa (scholarship).

Code Mixing: Another cognitive compensatory strategy used by the students to circumvent their linguistic difficulties was code-mixing, the transition from using linguistic units (words, phrases, clauses, etc.) of one language to using those of another within a single sentence (Kishe, 2017). The practice of code-mixing found in this study was the syntactical system from the NL stock was embedded to the syntactic system of the TL. For example, a student wrote a bedroom my sister, a bedroom my parent's (Indonesian: kamar tidur (bedroom), saudara perempuan (sister), saya (I, me,) orang tua (parent). Indonesian noun phrase is formed by placing the modifier after the noun modified (i.e., bedroom my sister, juice maggo) while in English the modifier is placed before the modifier (i.e., my sister's bedroom, maggo juice). What follows are the examples.

(1) To the right side of my bedroom is a bedroom my sister.

(2) She favorite food is chicken steak and the drink is jus mango.

(3) I have two rooms, a study room and a sleep room.

Literal Translation Switching: This includes translating literally a lexical item, idiom, compound word, or structure from NL to the TL without conveying the sense of the original one (Kishe, 2017). In this study, for examples, one student wrote seldom animal for endangered animal. The Indonesian word for seldom is langka and animal is binatang; therefore, binatang langka was litarraly translated into seldom animal. Another student wrote climb a carriage as a literal translation for Indonesian naik andong. Climb in English can be translated into naik and memanjat. What follows are the examples.

(1) Beside the study table is a cupboard.

(2) Komodo is a seldom animal on earth.

(3) We go around about Jogja City to climb a carriage.

(4) In Indonesia komodo is protection animal in komodo island.

Foreignizing Switching: The students also used foreignizing of Indonesian word and cognate; they used a NL word by adjusting it to L2 phonology (i.e., with an L2 pronunciation) and/or morphology (e.g., adding to it an L2 suffix) as their cognitive compansatory strategy (Kishe, 2017). In this study, the data showed the students used NL words by adjusting them to the morphology of the target language, adding English suffix -ic, -ble, -ity. For examples, 
they used the word electronica for electronic gadget which is in Indonesian barang elektronik/elektronika, the word karismatic for charismatic which is from Indonesian karismatik added with suffix -ic to sound English, and the word sociality that was created for sociable. The word sociality comes from Indonesian sosialitas added with English suffix -ity to sound English. What follows are the examples.

(1) In my house there is a lot of electronica such as television, AC, video player.

(2) The princess has good karismatic.

(3) All teachers and students in my school are very proud with the sociality of the head master.

(4) The goat had full energi after eat the grasses.

\section{Discussion of Findings}

The results of this study provide an empirical evidence of the occurance of NL (grammatical and lexical) switching as compensatory strategy of the EFL school students' written communication. The findings in general support the works of Chung (2006), Muin (2011), Das (2012), Jamshidi \& Navehebrahim (2013), Halim \& Maros (2014), Nyambura (2015), Zidouni (2016), Andayani (2016), Bhatti et.al, (2018), and Fitriani (2019) who maintained that during a communication in the $\mathrm{TL}$, the students filled the TL linguistic gaps using their NL repertoire. These also supports Oxford's (1990), Yaman et al.'s (2013) and Modupeola's (2013) works, illuminating that one of the roles of code switching was to serve as a referential function by compensating for the lack of lexical and grammatical knowledge in one language.

The current findings indicate that linguistic realization of compensatory strategy of NL switching on the students' written communication was found in the context of vocabulary as well as grammatical structure. This phenomenon may be explainable in terms of SLA perspective. It is believed that NL of the EFL learners plays a very important role in the learning process of second language. They tend to make use of the prior linguistic knowledge (NL) to construct and use new language or the TL. In other words, they tend to build their interim grammar by using their NL knowledge in the learning process of TL. EFL learners commonly think in NL first then translate their ideas to the TL (Ellis, 2006). So, NL switching is a common strategy for EFL learners to compensate their linguistic problem. And the students chose NL switching as an effective strategy to overcome communication difficulties or communication breakdown (Jamshidi \& Navehebrahim, 2013; Nyambura's, 2015; Zidouni, 2016; Andayani, 2016; Bhatti et al., 2018; Fitriani, 2019).

However, unlike the previous ones, the current findings disclose that the students switched to NL as compensatory strategy when dealing with cultural-loaded words, involving Indonesian naturalized borrowed words from Arabic, Indonesian words, Indonesian cognate, and Indonesian abbreviation. The students commonly found problems when dealing with cultural- bond expressions related to local food, religious practices, and educational terms. It is very likely that the students' use of English is consciously or unconsciously influenced by their culture. As it is commonly agreed that language is culturally embedded. Therefore, their culture is commonly present in their English oral and written communication as there is a strong connection between their inherited culture and the way they express themselves or communicate. Culture and communication are inseparable because culture determines how people encode messages and the meanings they have for messages (Samovar \& Porter, 1981). It is also likely that they do it with intention since such cultural bound expressions have no direct equivalents in English. As Armellino (2008) argues that it is unlikely to replace culturally-bound words or expressions from one language by the same words or expressions in another because the ideas behind the expressions are commonly related to the specific cultural context. Such words have become a linguistic trigger for NL switching. In the language production of bilinguals, the presence of these words can lead to a NL switching. This might be due to incorporation of elements of one language system into another. In this sense, the students were observed to switch to their NL lexicon only when they considered that these lexical items were transformable to the target language.

With respect to grammatical NL switching, the current findings support the works of Jamshidi \& Navehebrahim (2013), Nyambura (2015), Zidouni (2016), Andayani (2016), Bhatti, et al. (2018), and Fitriani (2019) which revealed that NL switching was used as communication strategy in EFL classroom, especially when they could not express their ideas in English. It was an effective strategy to overcome communication problems, especially due to different structural grammar between the two languages. However, these findings were not thoroughly explained cognitively.

The NL grammatical switching found in this study indicated that there was a tendency among the students to simplify the TL grammar, in a sense that they produced an proximative version of the TL. It is the similar mental process at work at the initial stage in L1 acquisition and in this study the students were at their initial stage of SLA, leading to a superficial grammatical knowledge of the TL, such as in their production of collocation, passive construction, negative construction, and conjunction. There was also a tendency to eliminate grammatical transformations, such as in their production of noun phrase.

In addition, similar to bilinguals, EFL learners have two language systems in one brain and both languages are active regardless of their intension to use one language only, the TL (Kroll, et al., 2015). Meanwhile, Guo et al.'s (2014) put it as different modes of thinking. They 
commonly think an idea in Indonesian first then translate it in English. In this way, the grammatical structure the students produced was very similar or even identical to the grammatical structure of their NL. Bhela in Derakhshan \& Karimi (2015) argues that when the learners feel gaps in their L2 grammatical structures for writing in L2, they use syntactical structures of their NL.

The different findings were also disclosed on the types of lexical and grammatical realization of the switching. This phenomenon was presumably due to the differences in the data used, the number of cases, and topics assigned to the participants. Since most data classifications were data driven the classification results also differed. This argument was supported by Moqimipour \& Shahrokhi (2015) who revealed that the type and frequency of lexical and grammatical switching depended much on the types of text the students wrote.

Yet, another different finding lies on the explicit revelation of cultural loaded words. This study revealed some lexical switchings which contain cultural loaded words, reflecting the specifics of Indonesian culture especially dealing with religious ritual and food. This occurrence is presumably the result of the difficulties confronted by the learners to express the ideas on these cultural elements. And this constitutes a prominent cause of NL switching in Indonesian EFL learners' written communication. In fact the students had problems to find English equivalence for such cultural bound expressions as their cultural manifestation. Derakhshan \& Karimi (2015) confirm that L2 learners tend to alternate the forms, meaning, and culture of their NL to the target language and culture when attempting to communicate in that language.

Moreover, the result of this study provides empirical evidence of how NL switching functions as a cognitive compensatory strategy which supports the results of the previous reviewed studies. They found that L2 students integrated their NL for the function of compensating L2 linguistic problems. However, the previous study results did not reveal how the strategies were employed by the learners. This constitutes another different finding from the current study. One thing is apparent from this study is that the learners' reliance on their NL functions as solution to the problems they have with the lexical and grammatical complexities of the TL and they do it through NL switching, code mixing, literal translation, and foreignizing. These four cognitive compensatory strategies were used to make up for their insufficient linguistic repertoire in order to achieve the written communication goal. Cook (2016) states that NL switching is psychologically-motivated strategy for solving the individual's L2 problem of expression. Meanwhile, Gou (2014) states that it is unrealistic to avoid NL in the process of learners' interlanguage development as this cognitive mechanism can facilitate learning. In other words, students use NL as coping strategy for the mismatch between their
L2 linguistic resources and communicative intentions. They resort to their NL to compensate for their deficiencies in the L2. In conclusion, NL switching in L2 written communication can function as both a cognitive learning strategy and as a cognitive compasatory strategy to solve commnunication problems.

\section{Conclusions and Implication}

The fact was that NL switching functioned as cognitive compensatory strategy used by the students to cope with the difficulty in lexicon, grammar, and cultural loaded words. The data clearly show that in EFL learning, NL switching is psychologically unavoidable. Learners commonly switch to their NL for various strategic purposes, including as compensatory strategy to bridge the existing linguistic and cultural gab.

In EFL learning, where the students have two or more language systems which co-exist in their brain, it is common that they frequently switch from one language to another in order to meet communication needs. In bilingualism this phenomenon is considered as a source of creativity in language. The pedagogical implication is that it is reasonable to consider NL switching as a cognitive strategy which must be studied to understand the cognitive process of L2 learning. The findings of this study could provide an influential argument for lessening the unfavorable beliefs that the use of L1 is merely a sign of laziness, sloppiness, or lack of competence.

NL switching behavior is an inevitable and necessary process as the students attempt to negotiate between their L2 repertoire and the communicative purposes. They employ NL switching as an effective strategy to achieve the communicative purposes. It is an effective strategic tool for the students to express their ideas. NL switching is part of communicative resources as well as learning experience. This information becomes important sources which help EFL teachers to understand more about their own teaching career and their students' problems. Teachers need to draw on different kinds of knowledge and experience in determining the teaching practices which are appropriate for their classrooms. If they can achieve some degree of understanding of how learners actually learn they could be able to utilize research findings in classroom teaching and materials preparation.

\section{Acknowledgements}

The authors would like to acknowledge Directorate General of Higher Education, Ministry of National Education, Indonesia for promoting and funding our research. Likewise, the contribution of the Research Center of Muhammadiyah University of Surakarta is deeply appreciated. 


\section{REFERENCES}

[1] Andayani, T. (2016). Code-switching, a communication strategy in learning English. Proceedings of the Fourth ISELT, 388-395.

[2] Armellino, E (2008). Translating culture-bound elements in subtitling: An example of interlinguistic analysis. Translation Journal, 12(2).

[3] Baker, M. (1992). In other words: A coursebook on translation. Routledge: London.

[4] Bhatti, A. Shamsudin, S. \& Said, S. M. (2018). Code-switching: A useful foreign language teaching tool in EFL classrooms. English Language Teaching, 11(6), 93-102.

[5] Brown, H. D. (2006). Principles of language learning and teaching. (4th edn.) White Plains, NY: Addison Wesley Longman, Inc.

[6] Cook, V. (2016). Second language learning and language teaching. Abingdon: Routledge.

[7] Chung, H.H. (2006). Code switching as a communicative strategy: A case study of Korean-English bilinguals. Bilingual Research Journal, 30 (2), 293-307.

[8] Das, B. (2012) code-switching as a communicative strategy in conversation. Global Media Journal - Indian Edition, 3(2), 2249-5835.

[9] Derakhshan, A. \& Karimi, E. (2015).The interference of first language and second language acquisition. Theory and Practice in Language Studies. 5(10), 2112-2117.

[10] Dornyei, Z., \& Scott, M. L. (1997). Communication strategies in a second language definitions and taxonomies. Language Learning. 47, 173-210.

[11] Ellis, N. C. (2006). Selective attention and transfer phenomena in L2 acquisition: Contingency, cue competition, salience, interference, overshadowing, blocking and perceptual learning. Applied Linguistics. 27(2), 164-194.

[12] Fitriani. N. (2019). Communication breakdown among Indonesian EFL learners: Barriers and strategies. ELTS Journal. 7(1), 35-41.

[13] Guan, C. \& Zhao, Y. (2016). An Investigation into culturally-loaded words teaching and learning by non-English majors. Open Journal of Modern Linguistics. $6(2), 37-42$.

[14] Guo, M., Liu. J., \& Chen, P. (2014). A case study on the effect of Chinese negative transfer on English writing. Theory and Practice in Language Studies. 4(9), 1941-1947.

[15] Halim, N.S. \& Maros, M. (2014). The functions of code-switching in facebook interactions. Procedia - Social and Behavioral Sciences, 118, 126- 133.

[16] James, C. (2014). Errors in language learning and use: Exploring error analysis: Applied linguistics and language study series. London: Routledge.
[17] Jamshidi, A. \& Navehebrahim, M. (2013). Learners Use of Code Switching in the English as a Foreign Language Classroom. The Journal of the AJBAS, 7(1): 186-190.

[18] Kishe, A. (2017). Language contact. Morrisville: LULU Press.

[19] Kroll, J., Bobb, S.C. \& Hoshino, N. (2015) Two languages in mind: Bilingualism as a tool to investigate language, cognition, and the brain. Curr Dir Psychol Sci, 23(3), 159-63.

[20] Markus, I. M. (2002) The teaching of passive constructions in Indonesian: An alternative approach. NUCB Journal of Language, Culture and Communication. 4(1), 33-39.

[21] Muin, A. (2011). Code switching as a communication strategy. Jurnal Adabiyah, 11(2), 264-277.

[22] Muysken, P. (2000). Bilingual speech: A typology of code-mixing. Cambridge: Cambridge. University Press.

[23] Myers-Scotton, C. (1989). Code-switching with English: Types of switching, types of communities. World Englishes, 8(1), 333-346.

[24] Modupeola, O.R. (2013). Code- Switching as a teaching strategy: Implication for English Language teaching and learning in a multilingual society. IOSR Journal of Humanities and Social Science. 14(3), 92-94.

[25] Nyambura, N.G. (2015) CODE-switching as a communication strategy in secondary schools: A case study of St.Francis Girls' High School, Mang'u. A master degree thesis retrieved from https://journalism.uonbi.ac.ke > chss > journalism.

[26] Olivares, Y. J. \& Fonseca, K. A. B. (2013). Developing writing skills through cognitive and compensatory learning strategies. Proceeding of Congreso Internacional De Lingüística Aplicada. Retrieved from www.literatura.una.a c.cr> category> 38 -ponencias.

[27] Oxford, R. (2003). Language learning strategies: An overview. Proceedings of GALA 2003 (Generative Approaches to Language Acquisition) Volume 1, 1-25.

[28] Poplack, S. (1913). Sometimes I'll start a sentence in Spanish y termino en español: Toward a typology of code-switching. Linguistics, 51, Issue Jubilee, 11-14. doi.org/10.1515/ling-2013-0039.

[29] Richards J. C. \& Schmidt, R. (2002). Longman dictionary of applied linguistics and language teaching. Harlow, UK: Longman.

[30] Samovar. L. A. \& Porter, R. E. (1981). Understanding intercultural communication. Belmont, California: Wadsworth Publishing Company.

[31] Zidouni, S. The Students' use of code switching as a Strategy to better communicate In EFL classroom. A dissertation. Retrieved from https://pdfs.semanticscholar.or $\mathrm{g} /$

[32] Yaman, S., Irgin, P., \& Kavasoglu, M. (2013). Communication strategies: Implications for EFL university students. 2(3), 254-164. 